\title{
Mass-spectrometry-based quantitation of Her2 in gastroesophageal tumor tissue: comparison to IHC and FISH
}

\author{
Daniel V. T. Catenacci ${ }^{1}$ - Wei-Li Liao ${ }^{2,3}$ - Lei Zhao ${ }^{4}$ Emma Whitcomb ${ }^{4}$. \\ Les Henderson ${ }^{1} \cdot$ Emily O$^{\prime} \mathrm{Day}^{1} \cdot{\text { Peng } \mathrm{Xu}^{1} \cdot \text { Sheeno Thyparambil }}^{2,3}$. \\ David Krizman ${ }^{2,3} \cdot$ Kathleen Bengali $^{2,3}$ - Jamar Uzzell ${ }^{2}$ - Marlene Darfler ${ }^{2,3}$. \\ Fabiola Cecchi $^{2,3}$ - Adele Blackler ${ }^{2,3} \cdot$ Yung-Jue Bang $^{5} \cdot$ John Hart $^{4}$. \\ Shu-Yuan $\mathrm{Xiao}^{4} \cdot$ Sang Mee Lee $^{6} \cdot$ Jon Burrows $^{2} \cdot$ Todd Hembrough ${ }^{2,3}$
}

Received: 11 May 2015/Accepted: 31 October 2015/Published online: 18 November 2015

(C) The International Gastric Cancer Association and The Japanese Gastric Cancer Association 2015

\begin{abstract}
Background Trastuzumab has shown a survival benefit in cases of Her2-positive gastroesophageal cancer (GEC). Immunohistochemistry (IHC) and fluorescence in situ hybridization (FISH) currently determine eligibility for trastuzumab-based therapy. However, these low-throughput assays often produce discordant or equivocal results.

Methods We developed a targeted proteomic assay based on selected reaction monitoring mass spectrometry (SRMMS) and quantified levels (amol/ $\mu \mathrm{g})$ of Her2-SRM protein in cell lines $(n=27)$ and GEC tissues $(n=139)$. We compared Her2-SRM protein expression with IHC/FISH, seeking to determine optimal SRM protein expression cutoffs in order to identify HER2 gene amplification.

Results After demonstrating assay development, precision, and stability, Her2-SRM protein measurement was observed to be highly concordant with the HER2/CEP17 ratio, particularly in a multivariate regression model adjusted for
\end{abstract}

Electronic supplementary material The online version of this article (doi:10.1007/s10120-015-0566-0) contains supplementary material, which is available to authorized users.

Daniel V. T. Catenacci

dcatenac@medicine.bsd.uchicago.edu

1 Department of Medicine, Section of Hematology/Oncology, University of Chicago Medical Center, Chicago, IL 60637, USA

2 OncoPlex Diagnostics Inc., Rockville, MD, USA

3 NantOmics, LLC, Culver City, CA, USA

4 Department of Pathology, University of Chicago, Chicago, IL, USA

5 Seoul National University College of Medicine, Seoul, Korea

6 Department of Public Health Studies, University of Chicago, Chicago, IL, USA
SRM expression of the covariates Met, Egfr, Her3, and HER2 heterogeneity, as well as their interactions (cell lines $r^{2}=0.9842$; FFPE $\left.r^{2}=0.7643\right)$. In GEC tissues, Her2SRM protein was detected at any level in $71.2 \%$ of cases. ROC curves demonstrated that Her2-SRM protein levels have a high specificity $(100 \%)$ at an upper-level cutoff of $>750 \mathrm{amol} / \mu \mathrm{g}$ and sensitivity of $75 \%$ at a lower-level cutoff of $<450 \mathrm{amol} / \mu \mathrm{g}$ for identifying HER2 FISH-amplified tumors. An "equivocal zone" of 450-750 amol/ $\mu \mathrm{g}$ of Her2-SRM protein was analogous to $\mathrm{IHC} 2+$ but represented fewer cases (9-16\% of cases versus 36-41\%).

Conclusions Compared to IHC, targeted SRM-Her2 proteomics provided more objective and quantitative Her2 expression with excellent HER2/CEP17 FISH correlation and fewer equivocal cases. Along with its multiplex capability for other relevant oncoproteins, these results demonstrate a refined HER2 protein expression assay for clinical application.

Keywords Her2 expression - HER2 (ERBB2) amplification · Gastric · Esophageal · Gastroesophageal adenocarcinoma - Stomach cancer - SRM-MS - Selected reaction monitoring mass spectrometry $\cdot$ Companion diagnostic $\cdot$ Clinical biomarker assay $\cdot$ Multiplex protein expression analysis in FFPE tissue

\author{
Abbreviations \\ SRM Selected reaction monitoring (mass spectrometry) \\ IHC Immunohistochemistry \\ FISH Fluorescence in situ hybridization
}

\section{Nomenclature}

HER2 Reference to the pathway in general

HER2 Reference to the gene

Her2 Reference to the protein 


\section{Introduction}

The human epidermal growth factor receptor-2 (HER2, $E R B B 2)$ is a receptor tyrosine kinase that promotes cell development, differentiation, and survival $[1,2]$. Aberrant HER2 activity due to gene amplification and consequent protein overexpression results in a HER2-driven oncogenic phenotype $[1,2]$. HER2 is amplified/overexpressed in various cancers, including breast $(\sim 20 \%)$, gastroesophageal (GEC) $(\sim 10-15 \%)$, and endometrial cancers $(\sim 12 \%)$ [3]. HER2 positivity is higher in esophageal/esophagogastric adenocarcinomas $(\sim 15 \%)$ than in distal gastric adenocarcinomas $(\sim 10 \%)[4,5]$. The Trastuzumab in the treatment Of GAstric cancer (ToGA) trial reported a survival benefit among HER2-positive GEC patients treated with trastuzumab-based therapy in comparison to standard chemotherapy, which led to the widespread incorporation of immunohistochemistry (IHC) and/or fluorescence in situ hybridization (FISH) testing into routine GEC care (see Fig. S1 in the Electronic supplementary material, ESM) [4].

ToGA trial eligibility defined HER2 positivity as either a positive FISH score (with any IHC score) or an IHC score of $3+$ (with any FISH score). However, the concordance between FISH and IHC is often variable. Patients whose tumors tested FISH positive/IHC negative ( $0-1+)$ comprised $22 \%$ of those enrolled; those patients derived no benefit from trastuzumab, which suggests that binary gene amplification status is imperfectly correlated with protein overexpression (Fig. S2 in the ESM). Consequently, Her2 IHC was subsequently validated in an independent cohort of GEC samples, and the clinical definition of HER2 positive changed to either IHC3+ or IHC2+/FISH positive (Figs. S1, S2 in the ESM) [6-9]. However, discordance between IHC and FISH results continues to affect anti-HER2 clinical trials. Ensuing Her2selective phase III GEC trials in the first-line (LOGiC) [10] and second-line (TyTAN) [11] metastatic settings evaluated chemotherapy plus either the HER2/Egfr-specific oral tyrosine kinase inhibitor lapatinib or a placebo. Both trials were negative for the primary endpoint of overall survival in the intention-to-treat populations. Interestingly, TyTAN enrolled 261 patients, of which $31 \%$ were FISH positive/IHC $0-1+$ [11]. Notably, the IHC3+/FISH-positive subset demonstrated a survival advantage (14 vs 7.6 months, HR 0.59, $p=0.0175$ ) [11]. Recently, a report suggested that the degree of HER 2 amplification/expression may be a better predictor of therapeutic benefit from anti-HER2 therapy [12]. These observations suggest the need for revised HER2 criteria/diagnostics, and also point to implications regarding optimal therapeutic strategies within classic HER2+ groups [13, 14].

Despite the noted utility of HER2 IHC and FISH, various reports detail numerous limitations [15-20]. IHC is semiquantitative; it attempts to incorporate staining intensity and extensity into a $0-3+$ scoring system. IHC is notoriously subjective and sensitive to antigen instability in formalinfixed paraffin-embedded (FFPE) unstained sections, as recently demonstrated [21-24]. HER2-equivocal (IHC2+) scores require reflex FISH analysis-accounting for almost $30 \%$ (159/584) of the FISH-positive cases in ToGA (Fig. S2a in the ESM), not including undocumented IHC2+/FISHnegative screen failures. Reflex FISH testing is laborious, may be time-consuming (especially serially after IHC), is costly if multiple genes are assessed, and remains operator dependent/subjective, particularly in molecularly heterogeneous cases [7, 25-28]. Both assays are low-throughput and result in delayed results and a less-than-economical use of limited tissue samples [13, 15, 19, 26]. Refinement of HER2 diagnostic methods is therefore to be encouraged.

Mass-spectrometry-based selected-reaction-monitoring (SRM-MS) targeted proteomics has gained broad acceptance as a specific and sensitive technology for quantifying levels of specific protein targets [29-31]. However, applying this technology to FFPE tissues has been technically challenging until recently. A multiplexed and quantitative Liquid Tissue-SRM method to quantify proteins in FFPE tissues based on unique peptide sequences does not have the same technical limitations as IHC/FISH [21-24].

We sought to evaluate the clinical role of quantitative Her2-SRM protein expression for GEC. Herein, we describe the application of the Her2-SRM protein assay to 27 cell lines and uniquely to 139 FFPE GEC tumors. After testing the precision and temporal reproducibility of the assay, we assessed the correlation of Her2-SRM protein levels with Her2 IHC/FISH scores, and performed multivariate modeling to account for HER2 heterogeneity and the SRM expression of the other relevant GEC oncoproteins Met, Egfr, and Her3. We determined optimal Her2-SRM expression cutoff values that correlated with the HER2/CEP17 FISH ratio for clinical application using ROC curves. Finally, clinical cases are presented to demonstrate the advantages of the "GEC-plex" assay, such as the ability to quantify multiple oncoproteins simultaneously, addressing issues around the current molecular profiling hurdles of inter- and intra-patient molecular heterogeneity.

\section{Materials and methods}

\section{GEC clinical samples and cell lines}

Patient GEC samples and cell lines were obtained from the University of Chicago (Chicago, IL, USA) under preapproved protocols (Tables S3, S6 in the ESM) $[23,32]$.

Cell-line mixing studies with HER2-amplified OE-19 and HER2-nonamplified MKN-1 to demonstrate dilutional effects of molecular subclones were performed under six 
lysate conditions with various ratios $(0 / 100,20 / 80,40 / 60$, 60/40, 80/20, 100/0).

\section{Sample preparation and Her2-SRM assay development}

Laser-microdissection-isolated cells were obtained from FFPE tumor sections, as previously described [21-24]. Total protein content of lysate was measured using a Micro-BCA assay (Thermo Fisher Scientific Inc., Rockford, IL, USA). Her2-SRM assay development followed previously described methods [21-24].

\section{Her2-SRM assay precision and temporal reproducibility}

Assay precision and temporal stability of the Her2-SRM assay were tested as previously described [23, 24].

\section{Quantitative analysis and validation of Her2 in clinical GEC tissues and cell lines}

Her2-SRM was calculated for 139 GEC FFPE samples and 27 cell lines from the ratio of the area under the curve (AUC) for the endogenous and isotopically labeled standard peptide multiplied by the known amount of isotopically labeled standard peptide spiked into the sample before analysis, as previously described [21-24].

\section{HER2 fluorescence in situ hybridization (FISH)}

FISH results were obtained through routine clinical testing of the HER2/CEP17 ratio. The majority of the samples that underwent clinical FISH testing were those with an initial Her2 IHC $2+$ score, per routine standards. FISH was retrospectively performed on samples with missing FISH results, as previously described $[32,33]$.

HER2 heterogeneity: FISH HER2 heterogeneity (hetero+) was defined as 10-50\% of enumerated nuclei with a HER2/CEP17 ratio of $\geq 2$ [26]. HER2 negative (HER2-) was defined as $<10 \%$ of scored nuclei having a ratio of $\geq 2$, and HER2+ (nonheterogeneous) was defined as $>50 \%$ of the scored nuclei having a ratio of $\geq 2$ [26].

\section{Her2 immunohistochemistry (IHC)}

IHC Her2 scores were obtained per routine clinical care using the Hercept Test kit from DAKO [6] (Figs. S1, S2 in the ESM). For samples without clinical Her2 IHC (e.g., archived curative-intent resections), when tissue was available, DABlabeled dextrose-based polymer complex bound to secondary antibody (Leica Microsystems Inc., Buffalo Grove, IL, USA) was performed, as previously described [34].

\section{Statistical methods}

To examine the association between Her2-SRM and HER2 gene copy number (GCN) or HER2/CEP17 ratio in cell lines and tissues, we used univariate and multivariate linear regression models with Her2-SRM as the independent and HER2 GCN or HER2/CEP17 ratio as the dependent variable. Multivariate models included SRM expression for Met, Egfr, and Her3, as well as their interaction terms, due to the putative influence of these proteins on HER 2 signaling. Presence of HER2 FISH heterogeneity was additionally included in the models. To compare IHC to either FISH or Her2-SRM in GEC tissues, we included indicators for $\mathrm{IHC} 2+$ and $\mathrm{IHC} 3+$ (IHC0/1+ reference category) in the regression model. To assess the most effective cutoff value for Her2-SRM for identifying the HER2/CEP17 ratio, we computed a receiver-operating-characteristic (ROC) curve. All analyses were performed using $\mathrm{R}$ software (www.r-project. org), version 3.0.1.

\section{Results}

\section{SRM assay development}

To develop the quantitative Her2-SRM assay, multiple peptides obtained from a tryptic digest of recombinant Her2 were measured using MS. The resulting three candidate peptides-SLTEILK, VLQGLPR, and ELVSEFSR-were then extensively screened in multiple formalin-fixed cell lines and FFPE clinical samples. The peptide ELVSEFSR provided the most reproducible peak heights, retention times, and chromatographic ion intensities, a clean elution profile, and distinctive/reproducible transition ion ratios; therefore, this peptide was selected for clinical assay development. SRM transitions used for the quantification of Her2 were selected based on the representative MS fragmentation spectrum for the peptide ELVSEFSR $\left[{ }^{13} \mathrm{C}_{6},{ }^{15} \mathrm{~N}_{4}\right]$ (Fig. 1a). A calibration curve was generated in formalin-fixed PC3 cell lysate to assess the linearity and the limits of detection and quantitation (LOD, LOQ) of the assay (Fig. 1b). Coefficients of variation (CVs) ranged from 2.20 to $14.04 \%$ for the samples (five replicates). The LOD and LOQ were 150 and 200 amol, respectively, with a linear regression value of $r^{2}=0.9998$. The linearity and small \%CV over the concentration range demonstrated the accuracy, reproducibility, and quantitative resolution of the assay. The total ion chromatograms for the light/heavy isotopically labeled peptides (Fig. 1c) and the transition ions (Fig. 1d) are shown. Fgfr2-SRM and Her3-SRM are detailed in Fig. S3 of the ESM. 
a

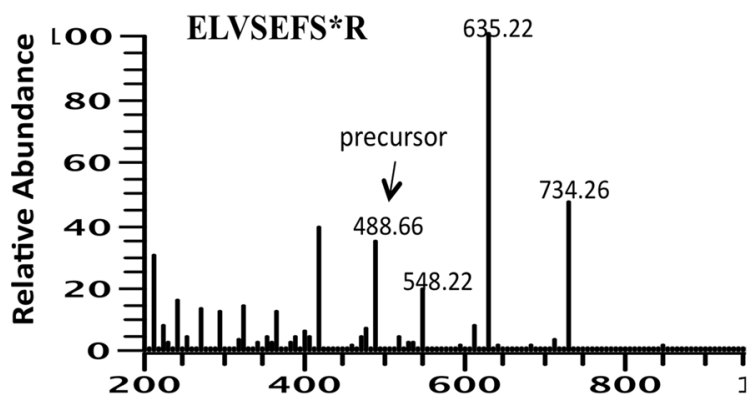

b

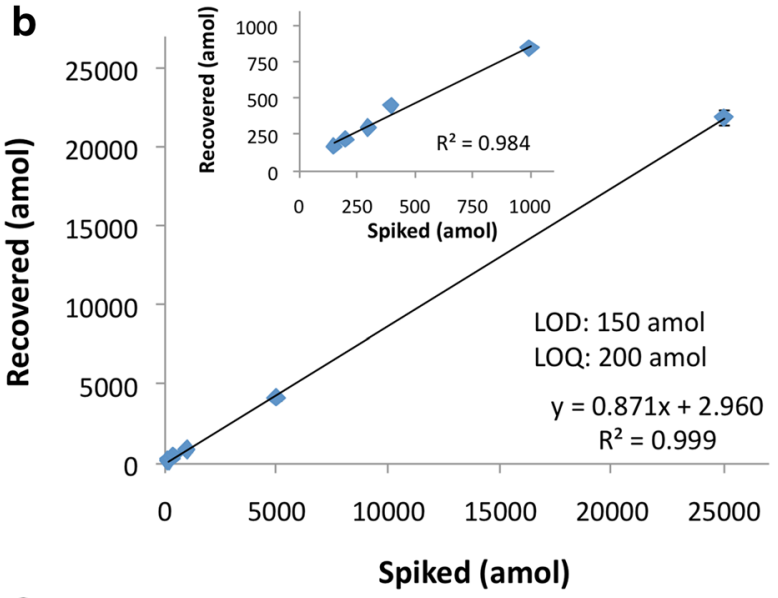

C

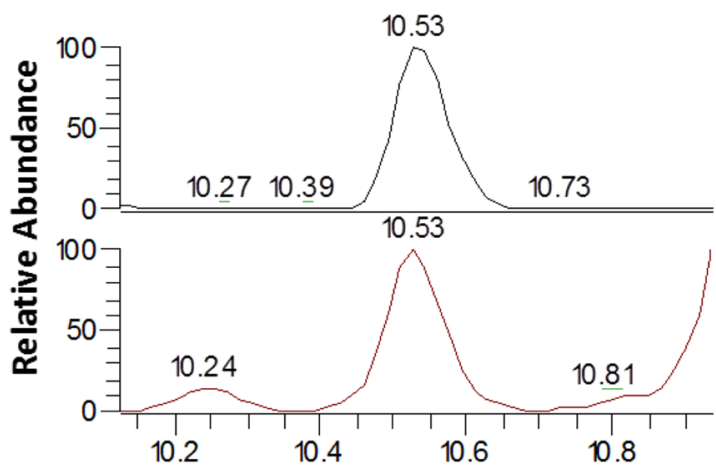

d

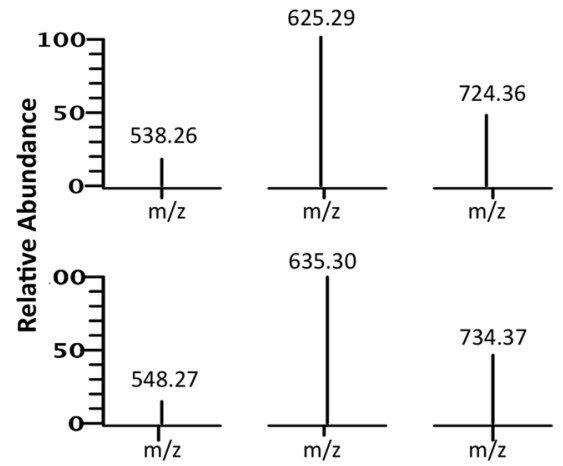

e
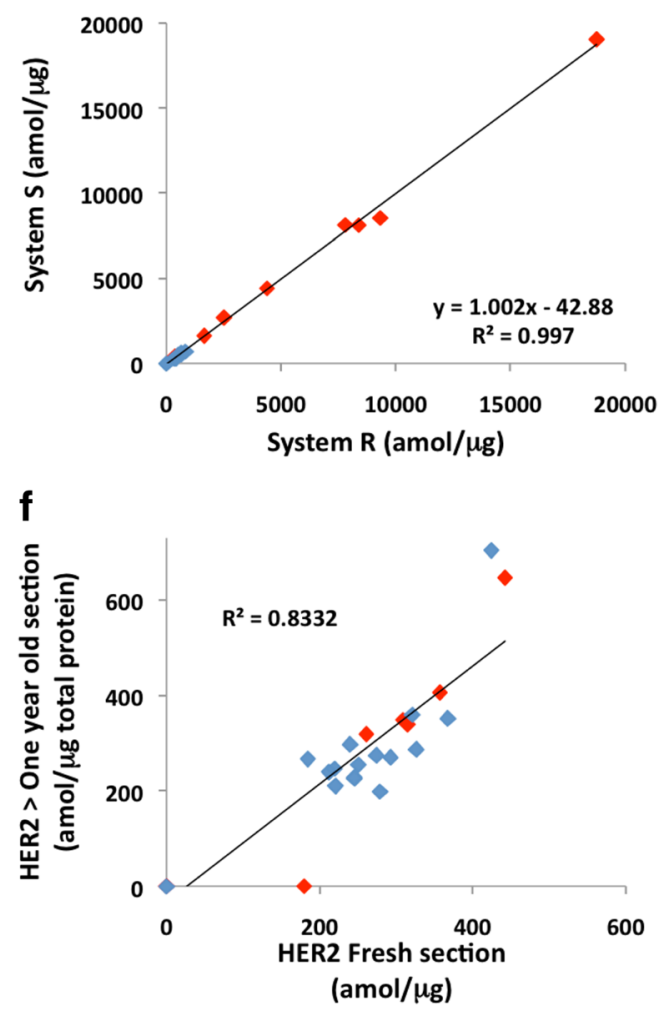

Fig. 1 Development of the Her2-SRM assay. a The fragmentation spectrum for the heavy ELVSEFSR peptide and $\mathbf{b}$ the standard curve generated in human PC3 cell lysate; inset: the standard curve generated without the highest two spiking points (5000 and 25,000 amol). Each point injected contained 5000 amol of heavy (ELVSEFSR $\left.\left[{ }^{13} \mathrm{C}_{6},{ }^{15} \mathrm{~N}_{4}\right]\right)$ on-column. c Total ion chromatograms for the

\section{Precision of the Her2-SRM assay}

To test assay precision, Her2 protein was measured in eight human breast cancer and eleven human GEC tissues. Using two different LC-MS systems and operators, all breast cancer samples were observed to express Her2 (range: 395.1-18896.7 amol/ $\mu \mathrm{g}$; CVs: 3.7-10.4 \%). Nine of eleven GEC samples expressed Her2 ( $\geq$ LOD) (range: 306-767.7 amol/ $\mu \mathrm{g}$; CVs: $7.5-14.6 \%$ ). The two operating systems light and heavy isotopically labeled peptides; $\mathbf{d}$ the transition ions used to identify and quantitate each peptide. e Precision assessment for measuring the Her2 levels in eight breast cancer (red) and eleven GEC (blue) FFPE tissues. f Temporal reproducibility of FFPE sections processed and analyzed using LT-SRM at two time points over a year apart [blue GEC $(n=18)$; red $\operatorname{NSCLC~}(n=9)$ ]

showed very good concordance $\left(r^{2}=0.9978\right)$, corroborating previous findings with other peptides (Fig. 1e, Table S1 of the ESM) [21, 23].

\section{Temporal reproducibility of the Her2-SRM assay}

To test the assay's temporal reproducibility, two sections from 18 GEC and 9 NSCLC samples were processed 13 months apart. The very good correlation $\left(r^{2}=0.8332\right)$ 
a

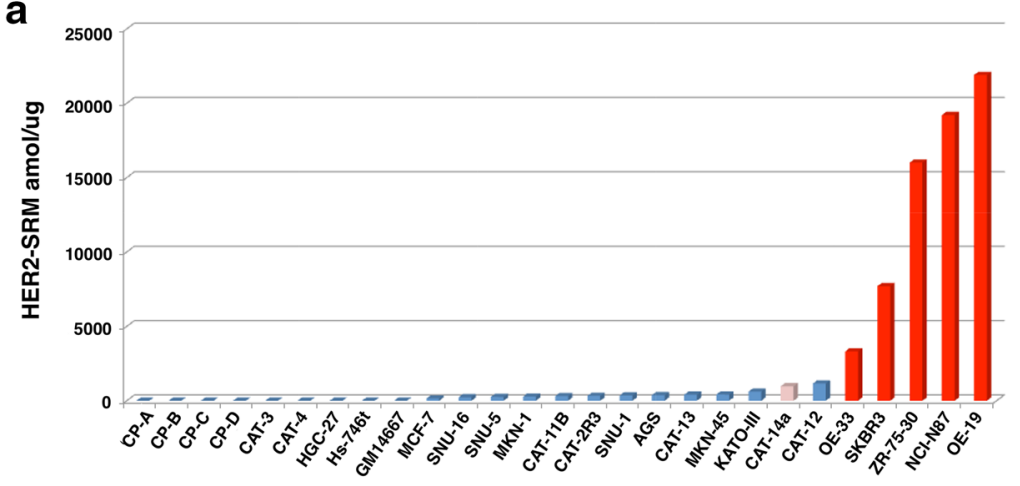

c

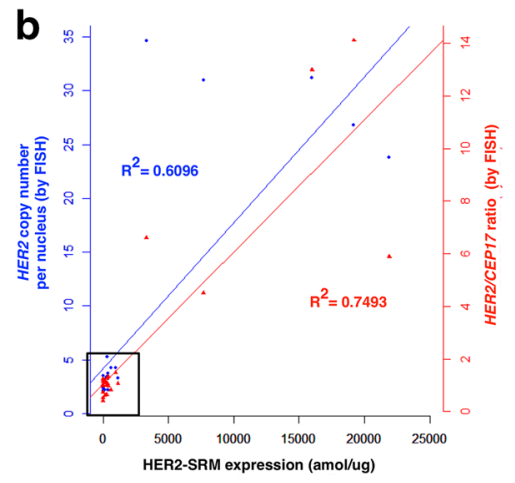

Fig. 2 Her 2 expression levels using LT-SRM, and correlation with HER2 gene amplification (by FISH) in 27 cell lines. a Quantification of Her2-SRM $(\mathrm{amol} / \mu \mathrm{g})$ for 27 cell lines including the GM15677 lymphoblast control. HER2-amplified cell lines (HER2/CEP17 ratio $\geq 2$ ) are indicated in dark red, and heterogeneous HER2 amplification in pink (see "Materials and methods" for hetero+ scoring). b Her2-SRM and FISH gene copy number (GCN) univariate correlations: the left $y$-axis (blue crosses) represents the mean HER2 GCN per nucleus and the right $y$-axis (red triangles) indicates the HER2/CEP17 ratio (see text for multivariate analysis including Egfr-,

observed supported the reproducibility of the Her2-SRM results in archival FFPE sections (Fig. 1f, Table S2 of the ESM).

\section{Correlation of Her2-SRM with FISH in cell lines and HER2 heterogeneity mixing studies}

The correlation of Her2-SRM expression and HER2 GCN or ratio was assessed in 27 GEC and breast cancer lines. (Figure 2, Table S3 of the ESM). Her2-SRM ranged from $<150$ to 21896.7 amol/ $\mu \mathrm{g}$ (Fig. 2a). Her2-SRM results correlated well with HER2 GCN and ratio in univariate analyses $\left(r^{2}=0.6096\right.$ and 0.7493 , respectively) (Fig. 2b, c). Adjusting for SRM expression of Met, Egfr, and Her3, the multivariate regression model resulted in improved and very good correlations of Her2-SRM with HER2 GCN and ratio $\left(r^{2}=0.8829\right.$ and 0.9842 , respectively) (Fig. S4 and Table S5 of the ESM). Using a preliminary cutoff of $1175 \mathrm{amol} / \mu \mathrm{g}$, derived from these data, Her2-SRM discerned cell lines with HER2 amplification
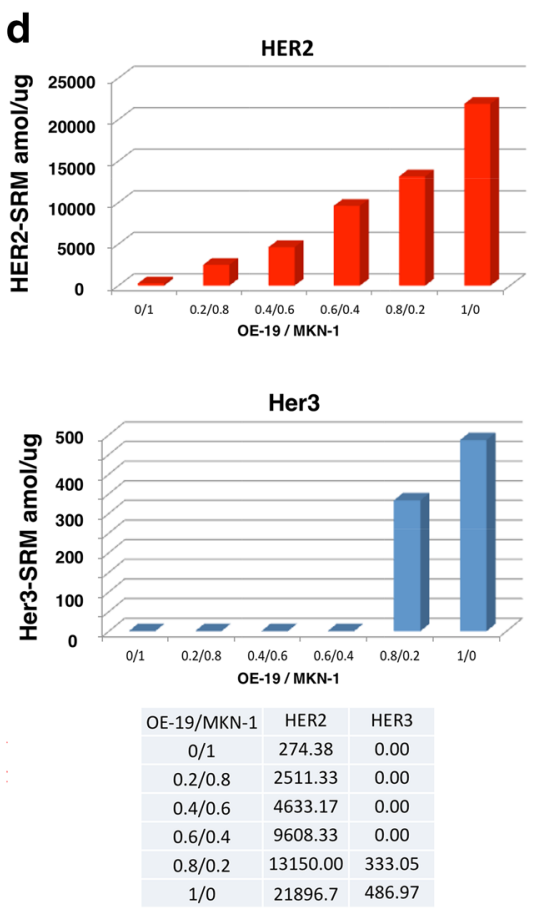

Her3-, and Met-SRM coexpression; GCN $R^{2}=0.8829$ and ratio $R^{2}=0.9824$ ). c Scatter plot of HER2 GCN/ratio (by FISH) (blue diamonds/red squares, respectively) and Her2-SRM expression in samples where Her 2 expression was $<1500 \mathrm{amol} / \mu \mathrm{g}$, represented by the black box in b. A preliminary Her2-SRM cutoff obtained from these cell-line data and correlating with HER2 amplification was determined as $\geq 1150 \mathrm{amol} / \mu \mathrm{g}$. d Her2-SRM (red) and Her3-SRM (blue) levels in a cell-line mixing study (OE-19: HER2 amplified/ MKN-1: HER2 nonamplified) modeling intratumor clonal heterogeneity

versus nonamplification with $100 \%$ sensitivity (5/5) and specificity $(22 / 22)$.

One cell line, CAT-14a, was observed to be HER2+/ hetero + , as $30 \%$ of its nuclei had a ratio $\geq 2$; the Her2SRM level was $969.33 \mathrm{amol} / \mu \mathrm{g}$, below the established cutoff of $1175 \mathrm{amol} / \mu \mathrm{g}$. To demonstrate the effects of stromal elements and clonal subpopulations within tumor masses [14, 23, 25-28, 34], a mixing study of HER2-amplified and -nonamplified cell lines (OE-19/MKN-1, respectively) was performed. This showed a dilutional effect of HER 2 expression upon decreasing OE-19 concentration, likely confirming the consequences of intratumoral HER2 heterogeneity, such as within CAT-14a (Fig. 2d).

\section{SRM, IHC, and FISH on FFPE samples}

Her2-SRM results were obtained for 139 GEC samples. Among this cohort, Her2 IHC was available for 122 samples. Fifty-one of these 122 IHC cases had FISH HER2/ 
CEP17 ratio results, and 42 had absolute GCN scores (see the sample flow chart in the ESM).

\section{Her2-SRM expression in FFPE samples and comparison to HER2 FISH}

Her2-SRM levels were quantitated in 139 GEC tumors (Table S4 of the ESM), and expression was above the LOD in $99 / 139(71.2 \%)$ samples, ranging from 150 to 24,671 amol/ $\mu \mathrm{g}$ (Fig. 3a).

Among cases with both Her2-SRM and either FISH $\operatorname{GCN}(n=42)$ or FISH ratio $(n=54)$ results, univariate analyses demonstrated fair/moderate correlations $\left(r^{2}=0.3615\right.$ and $r^{2}=0.5354$, respectively) (Fig. 3b). After incorporating HER2 FISH heterogeneity along with SRM coexpression of Met, Egfr, and Her3 (Fig. S4, Table S5), there was an improvement in the fit of the regression model, and good correlations of Her2-SRM with FISH GCN $\left(r^{2}=0.7345\right)$ and FISH ratio $\left(r^{2}=0.7643\right)$ were observed.

Optimal Her2-SRM cutoffs corresponding to a HER2/ CEP17 ratio $\geq 2$ were determined using a ROC curve (Fig. 3c). Upon exploring various cutoffs, $450 \mathrm{amol} / \mu \mathrm{g}$ was found to be $92.86 \%$ specific [95\% CI 83.33-100] and $75 \%$ sensitive [95\% CI 55-95] for identifying HER2 amplification by FISH; alternatively, a cutoff level of 750 amol $/ \mu \mathrm{g}$ was $100 \%$ specific (95\% CI 100-100) and $55 \%$ sensitive (95\% CI 30-75).

While most tumors had Her2-SRM levels $<450 \mathrm{amol} / \mu \mathrm{g}$ [112/139 (80.1\%)], a few samples had values $>750 \mathrm{amol} /$ $\mu \mathrm{g} \quad[14 / 139(10.1 \%)]$. Eleven of the 14 samples with $>750 \mathrm{amol} / \mu \mathrm{g}$ were available for FISH testing, and all of these (100\%) were FISH positive (mean ratio 9.28) - yielding a positive predictive value (PPV) of $100 \%$. A double cutoff level or equivocal zone was applied to better identify marginal HER2-positive cases (not unlike IHC2+ equivocal). Within the identified SRM equivocal zone of 450-750 amol/ $\mu \mathrm{g}$ there were 13 (9.4\%) samples (Figs. 3c, 5b). In terms of identifying a FISH ratio $\geq 2$, the performance of the upper/lower boundaries of this equivocal zone was evaluated using the 54 cases with both Her2-SRM and FISH ratio results (Figs. 3d, 5b). Of the 7 samples $(7 / 54,12.9 \%)$ between 450 and $750 \mathrm{amol} /$ $\mu \mathrm{g}$, there were $3 / 7(42.9 \%)$ that were deemed FISH negative (mean FISH ratio 1.28). Therefore, the PPV was $4 / 7$ $(57.1 \%)$. A lower mean ratio (3.04) was noted for the FISH-positive samples that fell within the Her2-SRM equivocal zone than for the samples with Her2$\mathrm{SRM}>750 \mathrm{amol} / \mu \mathrm{g}$ (Fig. $5 \mathrm{~b}$ ). Of the 36 samples with $<450 \mathrm{amol} / \mu \mathrm{g}$ (mean ratio 1.387$), 5(13.8 \%)$ were FISH positive (mean ratio 2.758 ), one $(2.78 \%$ ) was FISH equivocal, and the remaining 30 samples were FISH negative, demonstrating a negative predictive value (NPV) of $83.3 \%$. Depicting IHC, SRM, and FISH results sorted by IHC explicitly demonstrates the wide range of SRM expression within the $\mathrm{IHC} 2+$ and $3+$ categories and the large proportions of samples with very low Her2-SRM expression within these two groups, potentially leading to a better predictive capacity with respect to benefit from antiHER2 therapy (Fig. 5c). In summary, using the two SRM expression boundaries, the sensitivity of the lower boundary was $75 \%$ and the specificity of the upper boundary was $100 \%$ for discriminating a HER 2 FISH ratio $\geq 2$, and values within the Her2-SRM equivocal zone showed a FISH-positive PPV of $57.1 \%$ (Fig. 3d table).

\section{Comparison of Her2 IHC2+ status to FISH ratio and Her2-SRM in tissues}

Among tumors with HER2 tested by all three methods, there were 20/54 (37\%) that were IHC2+, of which 15 (75\%) were FISH negative and $5(25 \%)$ were FISH positive, demonstrating a PPV of $25 \%$ (Fig. 3e). By Her2SRM, $18(90 \%)$ of these IHC2+ samples were $<450$ amol/ $\mu \mathrm{g}$. Among all IHC samples, 44/122 (36\%) were IHC2+, with a FISH-positive PPV of $37.5 \%$ (Fig. 5a). The PPV for Her2-SRM was higher $(57 \%)$ within the 450-750 amol/ $\mu \mathrm{g}$ equivocal zone (Figs. 3d, 5b), suggesting that Her2-SRM was better at discriminating FISH amplification status than IHC.

\section{Comparison of IHC to FISH or Her2-SRM in tissues}

Among samples with both Her2 IHC and HER2 FISH GCN $(n=42)$ or HER2/CEP17 FISH ratio $(n=52)$, poor correlations were observed $\left(r^{2}=0.1959\right.$ and $r^{2}=0.1242$, respectively) (Fig. 4a, b). IHC2+ (referenced to IHC0/1+) was not associated with either FISH GCN or ratio; only IHC3+ was significantly associated with them ( $p=0.00578$ and $p=0.016$, respectively).

The subset of GEC samples $(n=122)$ that had both Her2 IHC (categorical variable) and Her2-SRM (linear variable) showed a very poor correlation, $r^{2}=0.0355$ (Fig. 4c). However, when comparing IHC to SRM with both treated as categorical variables, there was a notable dependence: $\chi^{2} p=0.02219$ (see table in Fig. 4c). To demonstrate the differences in sensitivity, specificity, and resolution between Her2 IHC and Her2-SRM, we compared the LODs for IHC $(\geq 1+)$ and Her2-SRM $(\geq 150 \mathrm{amol} / \mu \mathrm{g})$ (Fig. 4d). Of 122 cases, 108 (88.5\%) were $\geq \mathrm{IHC} 1+$, while $89 \quad(73 \%)$ samples wer$\mathrm{e} \geq 150 \mathrm{amol} / \mu \mathrm{g}$. IHC was $89.9 \%$ sensitive in identifying cases $\geq 150 \mathrm{amol} / \mu \mathrm{g}$, but only $15.2 \%$ specific in discerning SRM-negative cases. A score of IHC2+ was observed 

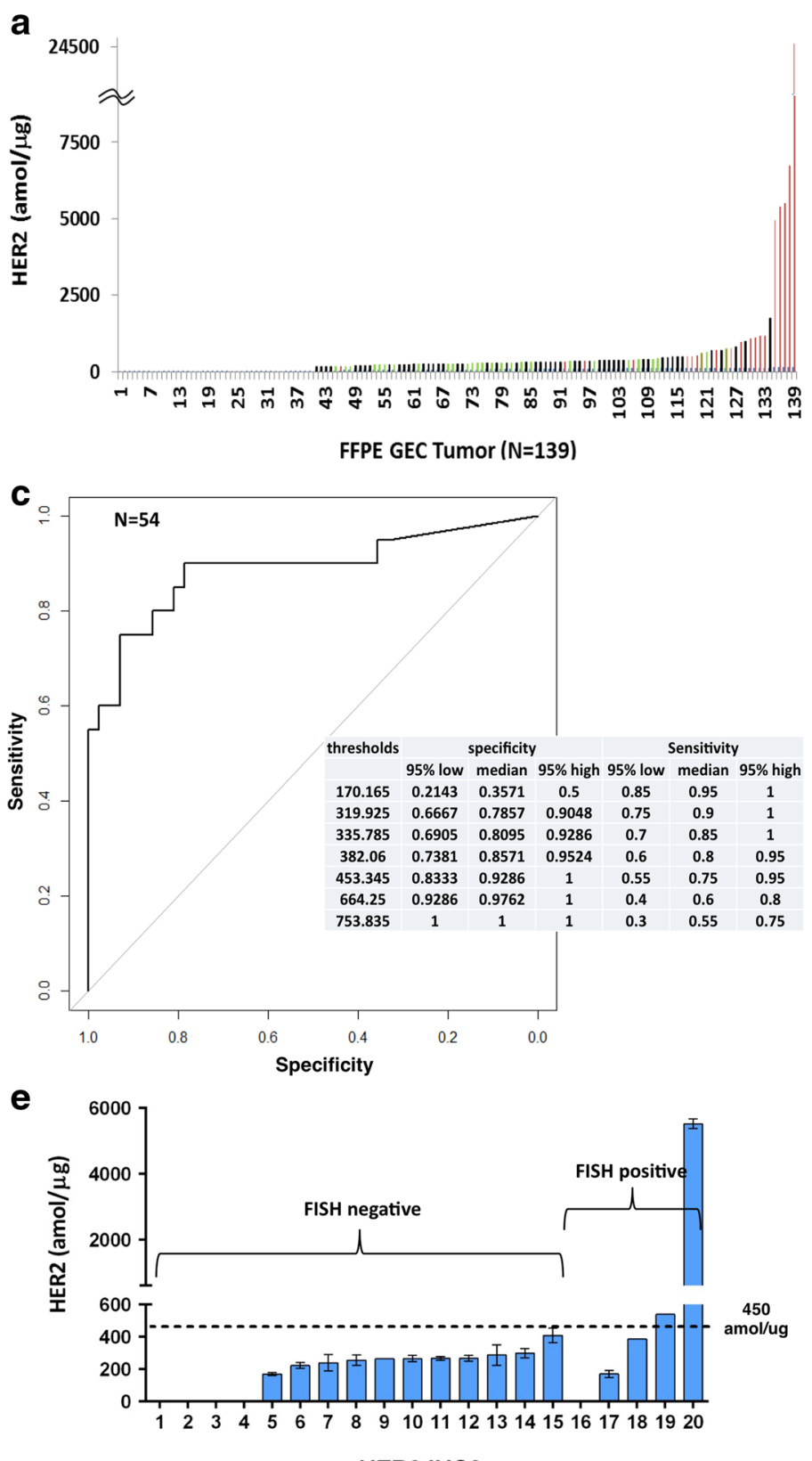

HER2 IHC2+

Fig. 3 Absolute levels of Her2 in GEC tissues and correlation of Her2-SRM levels with HER2 gene amplification. a Her2-SRM analysis of clinical FFPE GEC tissues $(n=139)$ ranging from $<150$ to $24,617 \mathrm{amol} / \mu \mathrm{g}$. Samples highlighted in red were shown by FISH to be HER2 amplified (HER2/CEP17 ratio $\geq 2$ ); nonamplified samples are depicted in green, and samples presented in black were not tested with FISH. b Univariate correlations of Her2-SRM with HER2 FISH GCN $\left(n=42\right.$, blue, $\left.r^{2}=0.3615\right)$ and ratio $(n=54$, red, $\left.r^{2}=0.5354\right)$. Multivariate analysis revealed stronger correlations when incorporating Met-SRM, Egfr-SRM, Her3-SRM, and HER2 FISH heterogeneity in the model: Her2-SRM:HER2 GCN, $r^{2}=0.7345$; Her2-SRM:HER2/CEP17 ratio, $r^{2}=0.7643$ (54 Her2SRM cases had the absolute FISH ratio available). c Optimal Her2SRM cutoff values determined by the receiver operating characteristic (ROC) curve with respect to a HER2/CEP17 ratio $\geq 2$. Using one cutoff level, a value of $450 \mathrm{amol} / \mu \mathrm{g}$ was $75 \%$ sensitive and $93 \%$
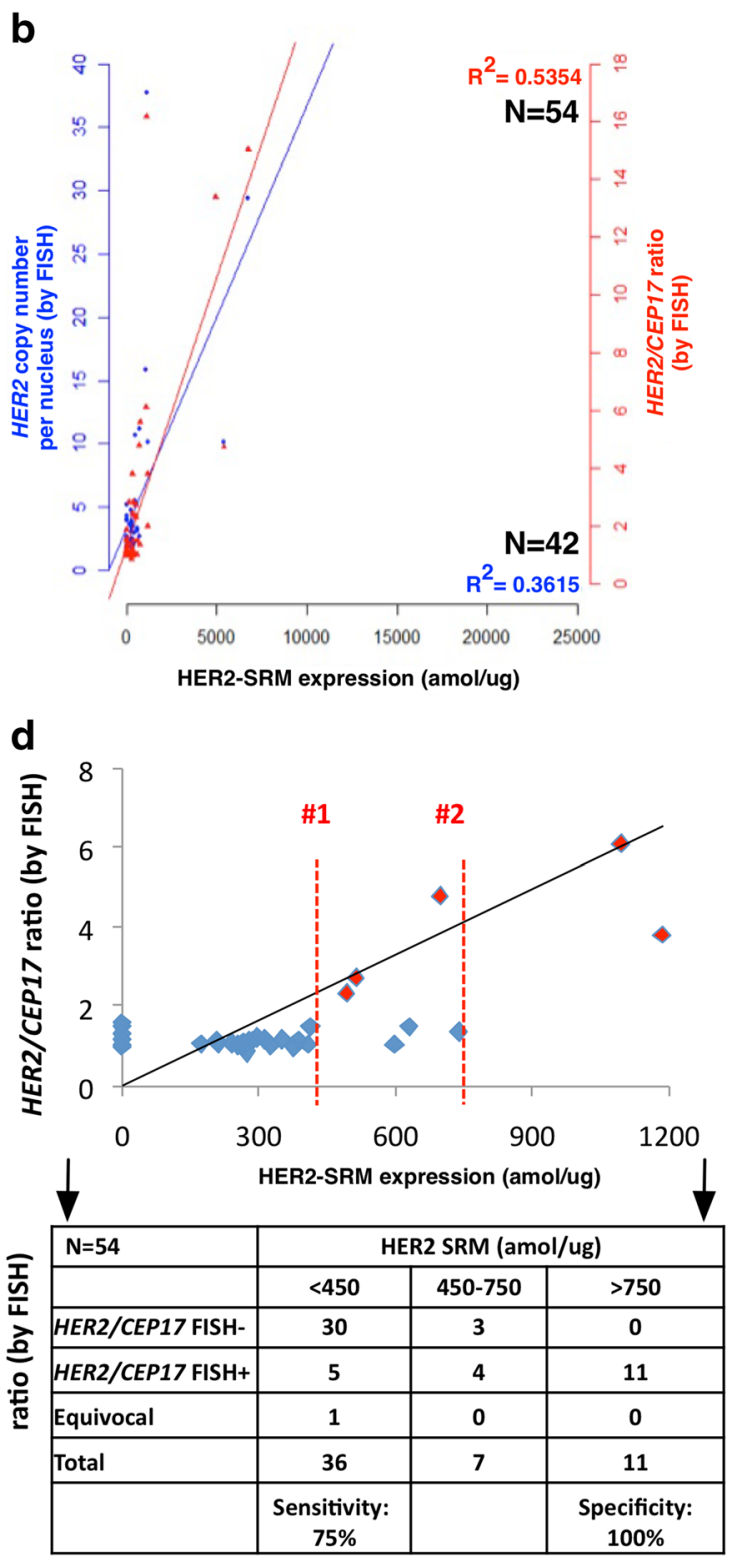

specific when identifying amplification; alternatively, a cutoff level of $750 \mathrm{amol} / \mu \mathrm{g}$ was $55 \%$ sensitive and $100 \%$ specific. d Using two cutoff points (analogous to $\mathrm{IHC} 0 / 1+=\mathrm{Her} 2$ negative, and IHC3 $+=$ Her2 positive), where values in-between (analogous to $\mathrm{IHC} 2+)=$ equivocal, an upper SRM level bound of $750 \mathrm{amol} / \mu \mathrm{g}$ and a lower bound of $450 \mathrm{amol} / \mu \mathrm{g}$ created an equivocal range of $450-750$ $\mathrm{amol} / \mu \mathrm{g}$. The two dotted red lines (\#1 and \#2) represent Her2-SRM expression that falls into this equivocal range $(n=9 / 54,16 \%)$. Fiftyfour cases were available with binary FISH ratio data $(\geq 2$ or $<2)$. It is currently recommended that the SRM-equivocal cases undergo confirmatory FISH testing. e Among tumors exhibiting Her2 IHC2 + with FISH results $(n=20), 15$ tumors (75 \%) were FISHand $5(25 \%)$ were FISH+. Her2-SRM expression levels are superimposed, demonstrating that the majority $(18,90 \%)$ of these IHC $2+$ samples were below the $450 \mathrm{amol} / \mu \mathrm{g}$ SRM cutoff 


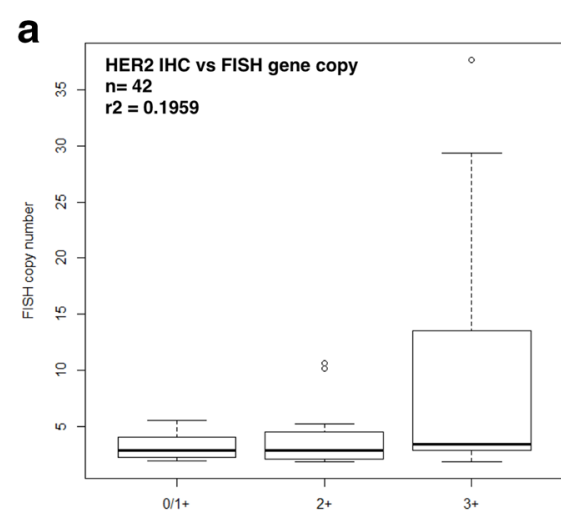

$\mathrm{IHC}$

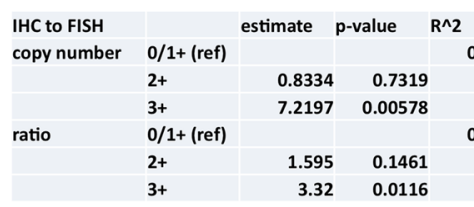

b

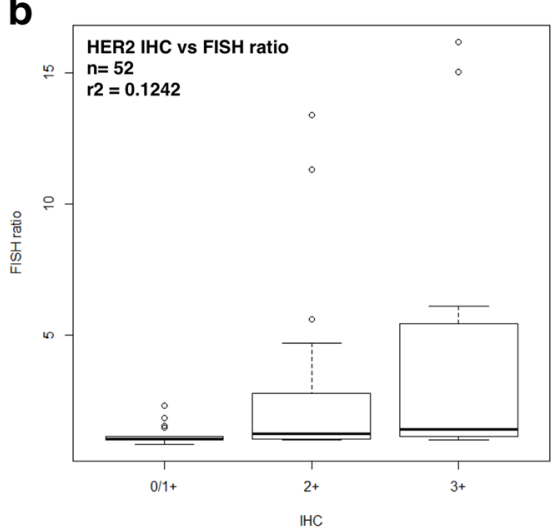

0.1959

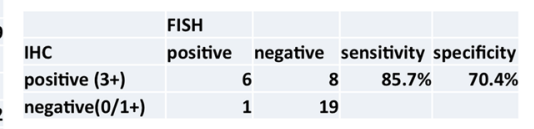

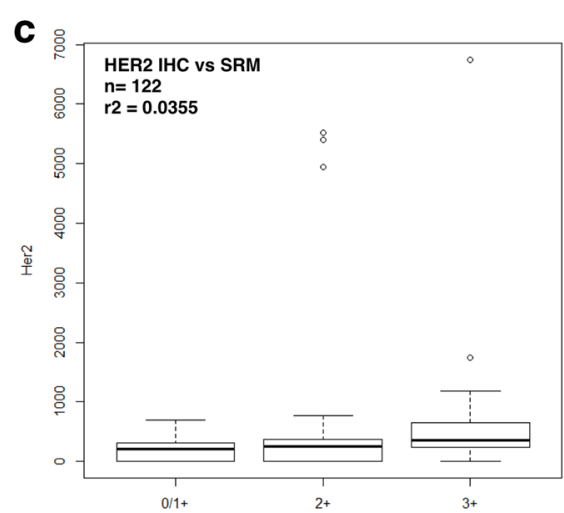

$\mathrm{HC}$

\begin{tabular}{|c|c|c|c|c|}
\hline $\begin{array}{c}\text { HER2-SRM } \\
<450\end{array}$ & $\begin{array}{c}\text { HER2-SRM } \\
450-750\end{array}$ & $\begin{array}{c}\text { HER2-SRM } \\
>750\end{array}$ & \\
\hline IHC 3+ & 23 & 5 & 7 & 35 \\
\hline IHC 2+ & 36 & 4 & 4 & $\underline{44}$ \\
\hline IHC 0/1+ & 40 & 3 & 0 & 43 \\
\hline missing & 13 & 1 & 3 & 17 \\
\hline & 112 & $\underline{13}$ & 14 & 139 \\
\hline
\end{tabular}
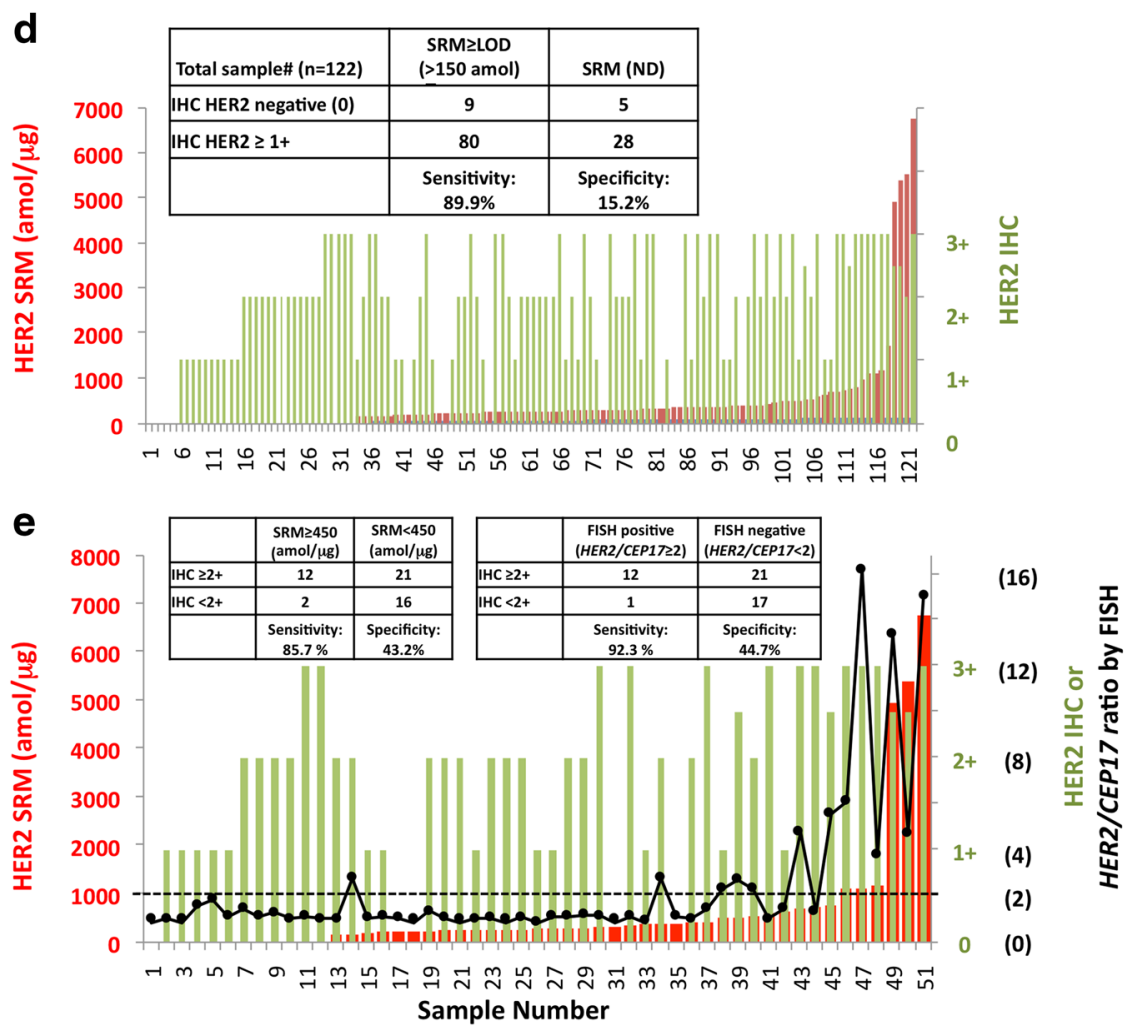

Fig. 4 Her2 IHC correlations with FISH assay and SRM. Correlations of Her2 IHC with a FISH GCN in 42 GEC tumors $\left(r^{2}=0.1959\right)$, b HER $2 / C E P 17$ ratio in $n=52$ GEC tumors $\left(r^{2}=0.1242\right)(52$ cases with IHC results also had absolute FISH ratio results), and c Her2-SRM (amol $/ \mu \mathrm{g}$ ) in $122 \mathrm{GEC}$ tumors $\left(r^{2}=0.0355\right)$. d IHC compared to Her2-SRM with an inset $2 \times 2$ table. e Three-way comparison of Her2-IHC, Her2-SRM, and HER2/

in $36 \%$ of all cases (44/122) (Fig. 5a), or $41 \%$ (21/51) of the cases available for a three-way comparison of IHC, SRM, and FISH ratio. These results revealed that Her2-
CEP17 ratio by FISH in 51 GEC tumors where all three values were available. Inset tables show the lower boundary for each assay (left, IHC2+ versus SRM $450 \mathrm{amol} / \mu \mathrm{g}$ ) and IHC2+ versus FISH (right). Red bars SRM, green bars IHC, black dots HER2/CEP17 ratio by FISH. Inset tables present the sensitivity/specificity of IHC assuming SRM (d, e) and FISH (b, e) as the comparative standards

SRM was better correlated with FISH ratio than IHC was; it showed better sensitivity and specificity for identifying a FISH ratio $\geq 2$ (Fig. $4 \mathrm{e}$ ). 


\section{Multivariate regression model with HER2 heterogeneity and multiplex SRM analysis of oncoproteins}

To test whether the correlation between Her2-SRM expression and HER2 FISH improved after adjusting for the covariates HER2-hetero+, Met-SRM, Egfr-SRM, and Her3-SRM for both the cell-line and tissue analyses, we evaluated a multivariate regression model (Fig. S4a, b and Table S5 in the ESM). Interactions were observed with Her3-SRM and Egfr-SRM (positive interactions) as well as Met-SRM and HER2-hetero+ (negative interactions) for the association of Her2-SRM with FISH GCN as well as with FISH ratio. These interactions were observed when either FISH status or Her2-SRM was the outcome variable.

\section{Clinical correlation with patient vignettes}

Patient 1, GEC181 (Fig. 6a), was diagnosed clinically with stage IV HER2-positive gastric cancer, yet there was a lack of baseline expression according to Her2-SRM ( $<150 \mathrm{amol} / \mu \mathrm{g}$, sample \#2 in Table S4 of the ESM) while Fgfr2-SRM was extremely high. Following rapid progression on anti-Her2 therapy, the patient responded to secondline Fgfr-specific tyrosine kinase inhibition.

Patient 2, GEC159 (Fig. 6b), was diagnosed with stage IV HER2 + esophagogastric cancer; extremely high baseline Her2-SRM levels were observed (24671 amol/ $\mu \mathrm{g}$, sample \#139 in Table S4 of the ESM). Upon interval treatments, serial primary tumor biopsies revealed interesting SRM-expression evolutionary patterns. Following initial trastuzumab exposure, a dramatic decrease $(-78.1 \%)$ in Her2-SRM was noted at first tumor progression. After treatment with trastuzumab and lapatinib, elevation of Her3-SRM $(+30.8 \%)$ was observed $(+58.9 \%$ from baseline). Subsequently, addition of pertuzumab led to clinical and biochemical responses with improved dysphagia/tumor markers. The patient is being maintained on this therapy 36 months from diagnosis.

\section{Discussion}

Current HER2 diagnostics have recognized limitations, and there is an urgent need for more objective, expedient, and "tissue-economic" assays in order to optimize clinical outcomes for patients [8, 13, 16, 20, 23, 35]. We developed a Her2-SRM assay within a multiplex proteomic quantification assay, and demonstrated its precision, stability, and reproducibility in cell lines and clinical FFPE samples, as well as correlations with IHC/FISH and other relevant oncoproteins (Her3/Egfr/Met).
We observed a wide range of Her2-SRM expression, not only within the entire GEC cohort $(N=139)$ but also within the sample subgroups of IHC3+ and FISH+ (range: <150-21896.7 amol/ $\mu \mathrm{g}$ ). Her2-SRM correlated well with HER2 FISH amplification status, reliably identifying highly amplified samples. The degree of HER2 amplification (HER2/CEP17 ratio) was linearly correlated with Her2-SRM, as was previously reported [36], just as the absolute $H E R 2 / C E P 17$ ratio was recently shown to correlate with the degree of anti-Her2 therapeutic benefit [12]. One criticism of the utilization of SRM technology in FFPE tissue is its low sensitivity to very low expression levels (i.e., <LOD). However, when considering geneamplified proteins, it was evident that the expression levels were dramatically higher than nonamplified expression levels, so this limitation does not appear to be relevant when applying the technology to the identification of geneamplified tumors. We have noted this for various genes/ proteins of interest [22, 23].

Most IHC2+ cases demonstrated little Her2-SRM expression. The equivocal zone that we defined for Her2SRM expression (450-750 amol/ $\mu \mathrm{g}$ ), which did not show a good correlation with the $H E R 2 / C E P 17$ ratio, represented approximately $10-15 \%$ of the cases-substantially lower than semiquantitative IHC2+ scoring $(\sim 35-40 \%)$. Within the respective equivocal zones, the PPV for Her2SRM was $57 \%$ compared to 25-37.5\% with IHC2+; others have demonstrated a PPV within IHC2+ as low as $13 \%$ [36]. Our IHC2+ rate is similar to that observed in the TOGA trial, particularly if their undocumented IHC2+/ FISH - cases are included. These $\mathrm{IHC} 2+$ rates represent the current experience in routine clinical care. Evaluating the performance of IHC versus Her2-SRM, as contrasted in Fig. 5, demonstrated the superiority of SRM over IHC in identifying truly FISH-positive HER2 samples and-importantly_relying less on reflex FISH testing.

In previous years, HER2 cutoffs for IHC and FISH that define eligibility for anti-Her2 therapy have erred towards lower thresholds, likely in order to avoid missing the potential benefit of anti-Her2 therapies in patients who would otherwise be given standard cytotoxics alone. However, a lack of benefit for these low-expressing subgroups is now recognized [4, 11]. Patient 1 was deemed clinically HER2 + yet Her2-SRM was low ( $<450 \mathrm{amol} /$ $\mu \mathrm{g}$ ); this ultimately predicted a lack of benefit from antiHer2 therapy. The ability to further stratify using Her2SRM within currently clinically accepted HER2+ patients may have significant treatment implications, as it would allow anti-HER2 therapy to be judiciously assigned only to those patients most likely to benefit from it while sparing the other patients from both the clinical and financial toxicity of such therapy. Further prospective validation is required in independent datasets, which is presently 
a
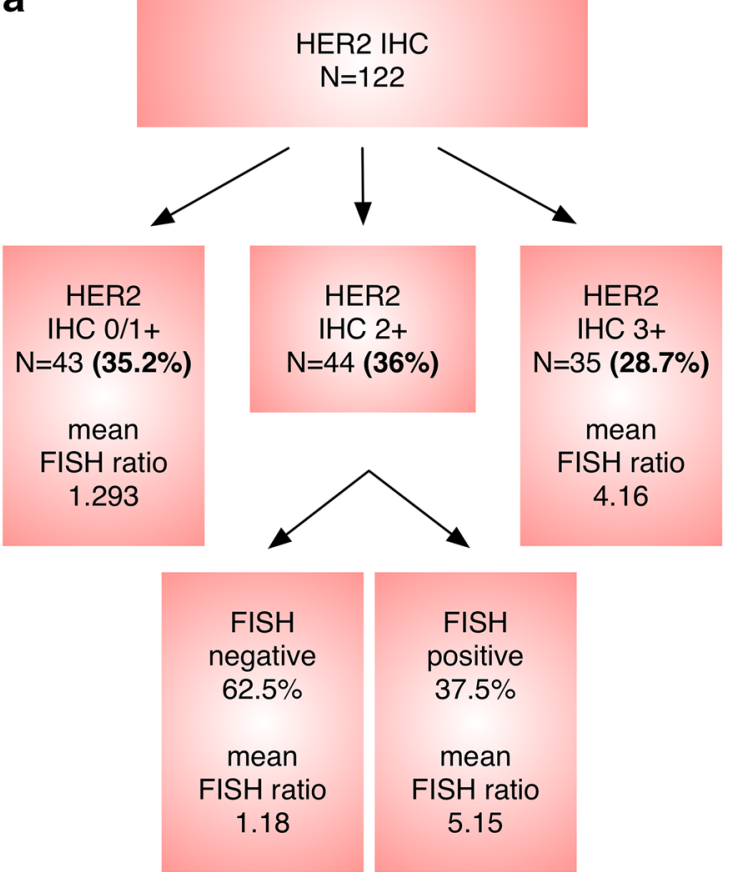

b
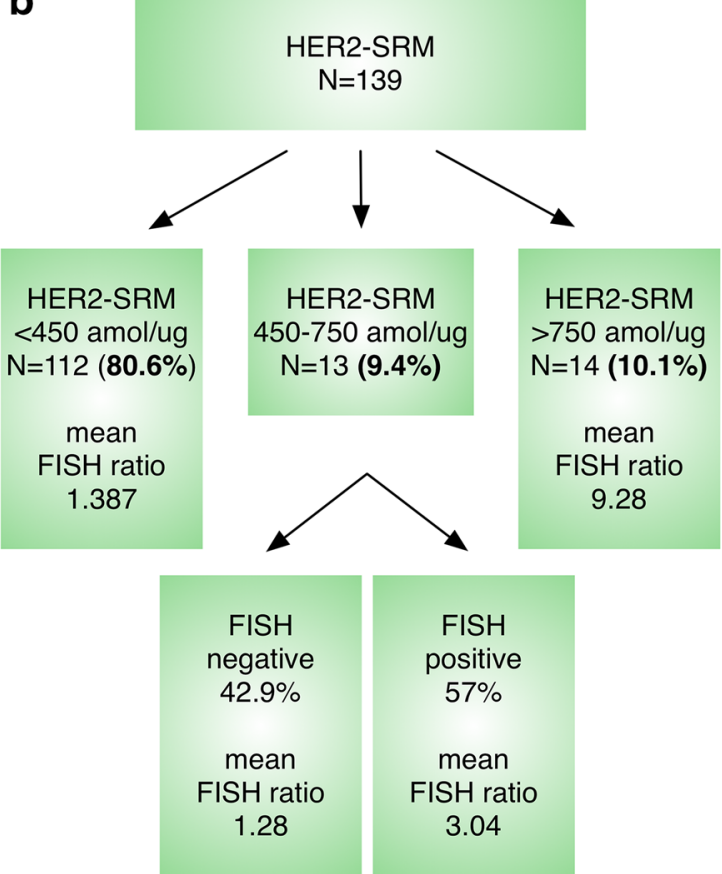

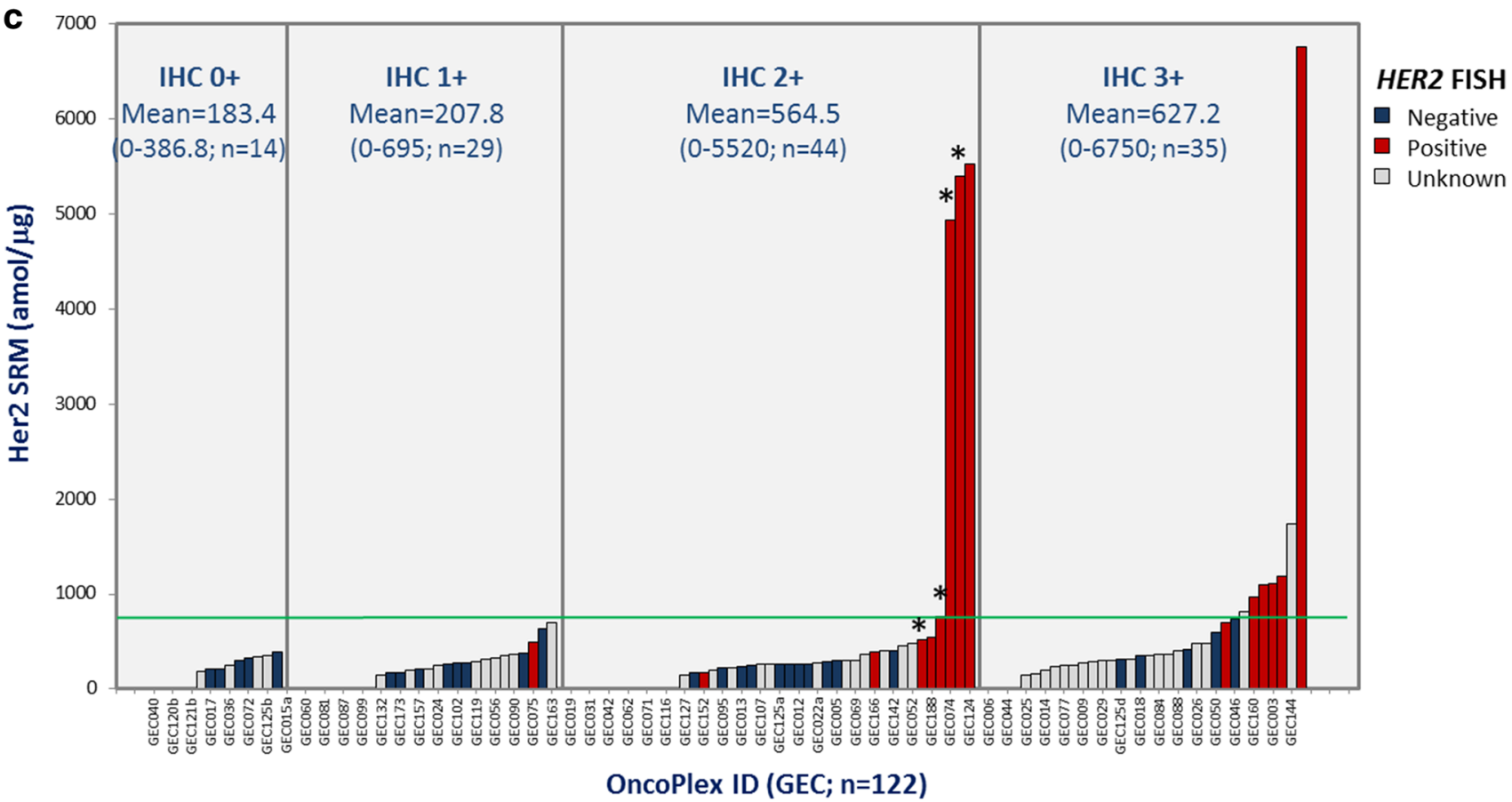

underway. Moreover, multiplex SRM testing to globally survey biomarkers may allow for optimal treatments towards most-likely tumor "drivers" to be administered as early as possible. In patient 1, very high Fgfr2 expression (consistent with FGFR2 amplification) may have trumped borderline/low Her2 expression. Trials testing prioritized personalized treatment algorithms based on higher throughput molecular profiling, including SRM-MS, are ongoing [14, 37].

The spatial intratumoral heterogeneity of FISH/IHC resulted in an observed dilutional Her2-SRM measurement, similar to the exemplary cell-line mixing study. It is likely that the identified Her2-SRM cutoff for cell lines was higher than that of tissues ( $>1175$ versus $>750 \mathrm{amol} / \mu \mathrm{g}$ ) 
4Fig. 5 Her2 status assessment of GEC cases by IHC (a) and Her2SRM (b) in order to identify HER2-positive and -negative cases, as determined by the underlying FISH HER2/CEP17 ratio. Both assays resulted in an equivocal zone for identifying underlying HER2 amplification (by a ratio $>2$ ). However, the incidence of the Her2SRM equivocal zone $(450-750 \mathrm{amol} / \mu \mathrm{g})$ was much lower $(9.4 \%)$ than that of IHC2+ (36\%). Within these Her2-SRM equivocal cases, the PPV was relatively high $(57 \%)$ compared to IHC2+ (PPV $37.5 \%$ ). Her2-SRM cases $>750 \mathrm{amol} / \mu \mathrm{g}$ presented a high mean HER2/CEP17 ratio (9.28) - and all of those cases were FISHamplified-as compared to IHC3 + (4.16). The mean ratio for Her2SRM equivocal cases that were FISH positive was 3.04, compared to 5.15 in $\mathrm{IHC} 2+/ \mathrm{FISH}+$ cases. Fewer equivocal cases requiring less reflex FISH testing along with better stratification of the HER2/ CEP17 ratio demonstrated the superiority of Her2-SRM over IHC. c Depicting these same IHC, SRM, and FISH results sorted by IHC category demonstrates the wide range of SRM expression within each IHC category, particularly the large proportion of samples with very low SRM expression within the $\mathrm{IHC} 2+$ and $\mathrm{IHC} 3+$ groups, potentially leading to better predictive capacity of Her2-SRM with respect to benefit from anti-HER2 therapy. Four cases were scored clinically as IHC2-3+ cases (denoted by an asterisk) (Table S4 in the ESM), and all four had a FISH ratio $>2$, with three cases having Her2-SRM $>750 \mathrm{amol} / \mu \mathrm{g}$ and one case between 450 and $750 \mathrm{amol} /$ $\mu \mathrm{g}$; these cases were included in the IHC2+ category given the uncertainty associated with the pathologist's score (i.e., equivocal) and the requirement for reflex FISH

due to fewer subclonal and stromal influences. Supporting this, the CAT-14a cell line, which demonstrated HER2 heterogeneity, possessed a Her2-SRM level (969.33 amol/ $\mu \mathrm{g})$ that was lower than the $1175 \mathrm{amol} / \mu \mathrm{g}$ cell-line cutoff. As such, the Her2-SRM assay on FFPE samples inherently captured intratumoral HER2 clonal heterogeneity by effectively providing an objective aggregate Her2 expression level representing all of the invasive tumor sampled via microdissection using standard $\mathrm{H} \& \mathrm{E}$ staining. As hypothesized, an improved correlation between Her2-SRM level and HER2/CEP17 ratio was observed when the HER2-heterogeneity status was included in the multivariate linear regression model. The improved correlation between SRM and FISH after adjusting for FISH heterogeneity was likely due to FISH scores reflecting certain select areas of the tumor, while SRM selected all of the $\mathrm{H} \& \mathrm{E}$ invasive tumor indiscriminately. A significant negative interaction between Her2-SRM level and presence of HER2 FISH heterogeneity was therefore demonstrated (lower than expected Her2-SRM levels in the presence of HER2 heterogeneity).

Her2 functional interactions with Met, Her3, and Egfr have been described [26, 36, 38-43]. Interestingly, after adjusting for these three covariates (Met/Her3/Egfr-SRM coexpression), a stronger linear correlation between Her2SRM and FISH HER2/CEP17 ratio was observed. Although the mechanisms for these interactions are not clearly defined, ultimately, gene amplification is a surrogate marker for protein overexpression. Specifically, the relationship between gene amplification and protein expression is likely multifactorial and may be influenced by the expression of other key oncoproteins within the cell. HER2-amplified tumors tended to have relatively low Her2-SRM levels if they were also highly expressing SRMMet as compared to HER2-amplified tumors that were not highly expressing SRM-Met. Supporting our findings, Met overexpression has been linked with resistance to anti-Her2 therapy for HER2-amplified tumors, and vice versa [38, 40]. On the other hand, Her3- and Egfr-SRM levels were observed to be positively associated with Her2-SRM levels, and both receptors have been implicated in signal transduction of HER2-amplified tumors. Regardless, further work to understand these associations more clearly is required. Notwithstanding, it is possible that incorporating these coexpression covariates-as is feasible with SRMMS multiplex technology—while assessing clinical outcome with anti-Her2 therapies will better identify mostlikely responders and may also direct better future multidrug targeted regimens [38, 40, 42, 44]. This is currently being assessed prospectively in a clinically linked independent dataset.

The ability to evaluate molecular heterogeneity longitudinally through time after treatment was demonstrated using the SRM-multiplex assay in patient 2. Extremely high Her2-SRM levels appeared to portend prolonged benefit from anti-Her2 trastuzumab therapy-approximately 12 months before first progression, twice the median progression-free survival in the ToGA study (segment 1-2 in Fig. 6b). At trastuzumab progression, Her2-SRM levels were $\sim 5$-fold lower, offering a potential mechanism of resistance by downregulating receptor expression, yet it remained well above IHC, FISH, and SRM cutoffs for HER2 positivity. Her2-SRM expression increased slightly after withdrawing trastuzumab for brief anti-PD1 therapy (segment 2-3), providing more evidence of continued HER2 addiction. This expression trend, along with previous evidence that maintaining therapeutic inhibition beyond progression upon a persistent oncogenic driver, provided a rationale for resuming trastuzumab-based therapy (segment 3-4) [14, 45-48]. After an initial response to the reintroduction of trastuzumab-based therapy there was further progression, but "vertical inhibition" with lapatinib/trastuzumab led to a continued response (segment 4-5) [48, 49]. Finally, evolution towards higher Her3-SRM expression suggested another mechanism of resistance; pertuzumab-based therapy was then introduced with clinical benefit (segments 5-6 to present) [36, 43, 50]. Serial testing in order to re-target therapies based on real-time molecular profiles merits further testing in ongoing novel prospective clinical trial designs [14]. 
a
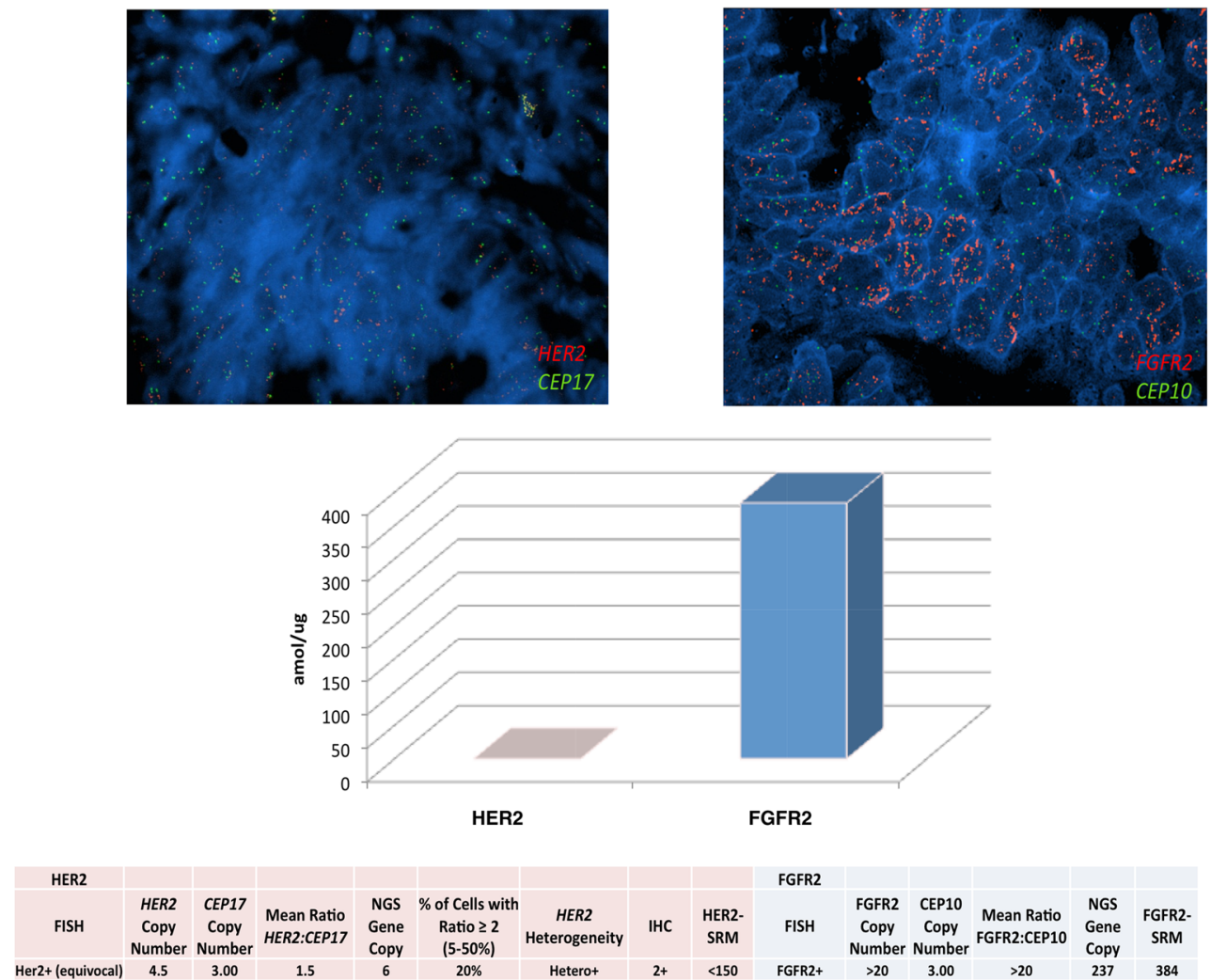

b

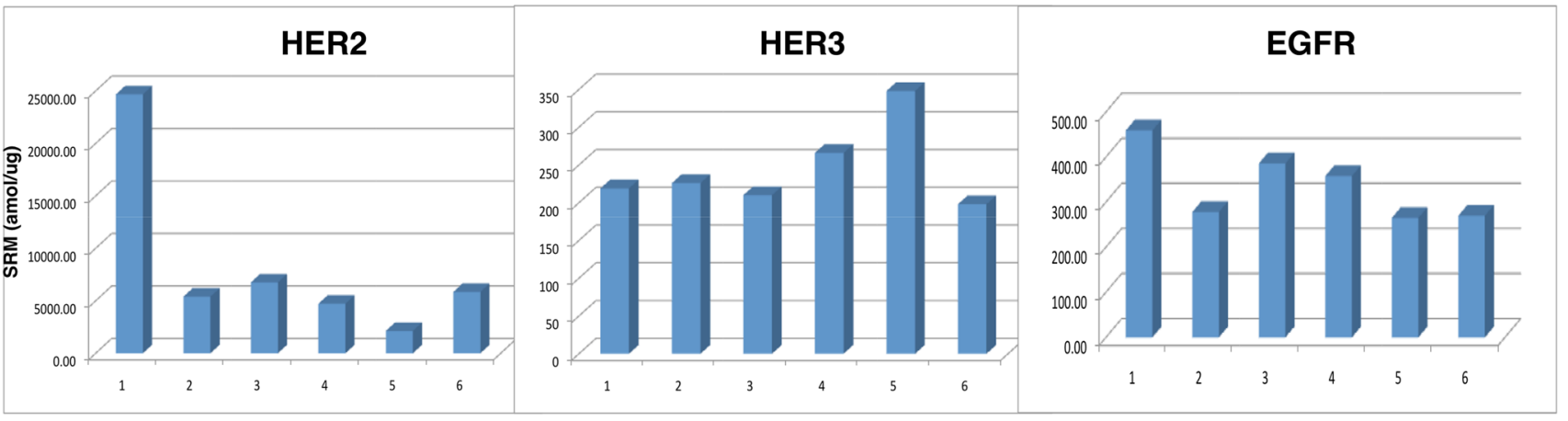

Fig. 6 a Molecular profiling and a call for treatment prioritization based on degree of genomic/proteomic aberration. A GEC patient was diagnosed clinically as HER2 + based on IHC2+ and FISH, yet a more appropriate drug pairing was suggested by SRM multiplex testing (Fgfr2). Her2-SRM was observed to be $<150 \mathrm{amol} / \mu \mathrm{g}$ (the range observed in all preclinical/clinical samples to date is $<150-26170 \mathrm{amol} / \mu \mathrm{g}$ ), while Fgfr2-SRM was observed to be 384 amol/ $\mu \mathrm{g}$ (above the 95th percentile of documented Fgfr2 expression). $N G S$ next-generation sequencing. b Serial Her2-SRM, Her3-SRM, and Egfr-SRM levels over time/treatment of a Her2-overexpressing and HER2-gene-amplified esophageal tumor of a 39-year-old man. Segment 1-2: first-line cisplatin/irinotecan-trastuzumab for 6 cycles (D1, D8 q 21 days) was not well tolerated; RT to lumbar metastases; second-line FOLFIRI - trastuzumab 12 doses, SD but increasing tumor markers/bleeding. Segment 2-3: embolization to bleeding primary tumor; third-line anti-PD1 antibody (PDL1+IHC), 3 biweekly doses then PD (new multiple liver metastases). Segment 3-4: fourth-line docetaxel-trastuzumab 10 cycles, then recurrent primary tumor bleeding but SD. Segment 4-5: RT 20 Gy 1/2014-2/ 2014 to bleeding primary tumor. Fifth-line lapatinib/paclitaxel plus trastuzumab (15 biweekly cycles then PD on CT as well as PD clinically and by tumor markers). Segment 5-6: sixth-line FOLFOXtrastuzumab/pertuzumab, stable disease on CT with slight progression of tumor markers. Segment 6 to present: FOLFIRINOX-trastuzumab/ pertuzumab for three cycles, response in tumor markers and PR on CT. Biopsy time points (all via EGD of primary tumor, except \#6liver core biopsy): 1 5/22/2012, 2 6/10/2013, 3 10/30/2013, 4 1/14/ 2014, 5 10/7/2014, 6 12/17/15. Diagnosed with symptoms 1/2012, ultimate tissue diagnosis 5/2012 with stage IV disease (bone, M1 lymph nodes) - now almost 36 months from onset of symptoms, 33 months from biopsy (as of 2/2015) 
Compared to IHC, SRM-MS provided more quantitative Her2 expression with a better HER2 FISH correlation and a narrower equivocal zone. Ultimately, FISH testing for HER2 amplification is a surrogate for Her2 protein overexpression, and we showed that this expression level is influenced by several factors, including absolute HER2/ CEP17 ratio and HER2 heterogeneity within the sample along with the coexpression levels of various other critical oncoproteins. Therefore, a single Her2-SRM expression cutoff in the context of the SRM-MS "GEC-plex" may better predict anti-HER2 therapeutic benefit without the need to rely on FISH or IHC. This is the subject of ongoing evaluation and validation in a large cohort of clinically linked samples. Along with the multiplex capability, permitting the quantification of other protein biomarkers, these results demonstrate a refined Her2 expression assay for clinical application.

Acknowledgments D.V.T.C. would like to thank Drs. Hedy Kindler, Ravi Salgia, Funmi Olopade, and Mitchell Posner for their continued support. All of the authors would like to thank Dr. Michael F. Press (University of Southern California) for his thoughtful and critical review of this manuscript. The authors would like to thank Dr. Zev Wainburg (UCLA) for provision of the cell line MKN-1.

Grant support This work was supported by NIH K12 award (CA139160-01A), NIH K23 award (CA178203-01A1), UCCCC (University of Chicago Comprehensive Cancer Center) Award in Precision Oncology-CCSG (Cancer Center Support Grant) (P30 CA014599), Cancer Research Foundation Young Investigator Award, ALLIANCE for Clinical Trials in Oncology Foundation Young Investigator Award, Oncoplex Dx Collaborative Research Agreement, LLK (Live Like Katie) Foundation Award, and the Sal Ferrara II Fund for PANGEA (to D.V.T.C).

\section{Compliance with ethical standards}

Ethics statement All procedures followed were in accordance with the ethical standards of the responsible committee on human experimentation (institutional and national) and with the Helsinki Declaration of 1964 and later versions. Informed consent or substitute for it was obtained from all patients for being included in the study.

Disclosures WLL, ST, KB, JU, MD, DBK, FC, AB, TH, and JB are/were paid employees and stock owners at Oncoplex Dx and/or NantOmics, LLC. DVTC received collaborative research funding from Oncoplex Dx.

\section{References}

1. Slamon DJ, Clark GM, Wong SG, et al. Human breast cancer: correlation of relapse and survival with amplification of the HER2/neu oncogene. Science. 1987;235:177-82.

2. Natali PG, Nicotra MR, Bigotti A, et al. Expression of the p185 encoded by HER 2 oncogene in normal and transformed human tissues. Int J Cancer. 1990;45:457-61.

3. Slamon DJ, deKernion JB, Verma IM, Cline MJ. Expression of cellular oncogenes in human malignancies. Science. 1984;224:256-62.
4. Bang YJ, Van Cutsem E, Feyereislova A, et al. Trastuzumab in combination with chemotherapy versus chemotherapy alone for treatment of HER2-positive advanced gastric or gastro-oesophageal junction cancer (ToGA): a phase 3, open-label, randomised controlled trial. Lancet. 2010;376:687-97.

5. Sehdev A, Catenacci DV. Gastroesophageal cancer: focus on epidemiology, classification, and staging. Discov Med. 2013;16:103-11.

6. Hofmann M, Stoss O, Shi D, et al. Assessment of a HER2 scoring system for gastric cancer: results from a validation study. Histopathology. 2008;52:797-805.

7. Ruschoff J, Dietel M, Baretton G, et al. HER2 diagnostics in gastric cancer-guideline validation and development of standardized immunohistochemical testing. Virchows Archiv Int J Pathol. 2010;457:299-307.

8. Ruschoff J, Hanna W, Bilous M et al. HER2 testing in gastric cancer: a practical approach. Mod Pathol. 2012;25:637-650.

9. Bartley AN, Christ J, Fitzgibbons PL et al. Template for reporting results of HER2 (ERBB2) biomarker testing of specimens from patients with adenocarcinoma of the stomach or esophagogastric junction. Arch Pathol Lab Med 2015;139:618-620.

10. Hecht JR, Bang YJ, Qin S et al. Lapatinib in combination with capecitabine plus oxaliplatin (CapeOx) in HER2-positive advanced or metastatic gastric, esophgael, or gastroesophageal adenocarcinoma (AC): the TRIO-013/LOGiC Trial. J Clin Oncol. 2013;31:abstr LBA4001.

11. Satoh T, Xu RH, Chung $\mathrm{HC}$, et al. Lapatinib plus paclitaxel versus paclitaxel alone in the second-line treatment of HER2amplified advanced gastric cancer in Asian populations: TyTAN-a randomized, phase III study. J Clin Oncol Off J Am Soc Clin Oncol. 2014;32:2039-49.

12. Gomez-Martin C, Plaza JC, Pazo-Cid R, et al. Level of HER2 gene amplification predicts response and overall survival in HER2-positive advanced gastric cancer treated with trastuzumab. J Clin Oncol Off J Am Soc Clin Oncol. 2013;31:4445-52.

13. Khoury JD, Catenacci DV. Next-generation companion diagnostics: promises, challenges, and solutions. Arch Pathol Lab Med. 2015;139:11-3.

14. Catenacci DVT. Next-generation clinical trials: novel strategies to address the challenge of tumor molecular heterogeneity. Mol Oncol. 2015;9:967-996.

15. Allison M. The HER2 testing conundrum. Nat Biotechnol. 2010;28:117-9.

16. Carlson B. HER2 tests: how do we choose? Biotechnol Healthc. 2008;5:23-7.

17. Cho EY, Srivastava A, Park K, et al. Comparison of four immunohistochemical tests and FISH for measuring HER2 expression in gastric carcinomas. Pathology. 2012;44:216-20.

18. Buza N, English DP, Santin AD, Hui P. Toward standard HER2 testing of endometrial serous carcinoma: 4-year experience at a large academic center and recommendations for clinical practice. Mod Pathol. 2013;26:1605-1612.

19. McCullough AE, Dell'orto P, Reinholz MM, et al. Central pathology laboratory review of HER2 and ER in early breast cancer: an ALTTO trial [BIG 2-06/NCCTG N063D (Alliance)] ring study. Breast Cancer Res Treat. 2014;143:485-92.

20. O'Hurley G, Sjostedt E, Rahman A, et al. Garbage in, garbage out: a critical evaluation of strategies used for validation of immunohistochemical biomarkers. Mol Oncol. 2014;8:783-98.

21. Hembrough T, Thyparambil S, Liao WL, et al. Application of selected reaction monitoring for multiplex quantification of clinically validated biomarkers in formalin-fixed, paraffin-embedded tumor tissue. J Mol Diag. 2013;15:454-65.

22. Hembrough T, Thyparambil S, Liao WL, et al. Selected reaction monitoring (SRM) analysis of epidermal growth factor receptor (EGFR) in formalin fixed tumor tissue. Clin Proteom. 2012;9:5. 
23. Catenacci DV, Liao WL, Thyparambil S, et al. Absolute quantitation of Met using mass spectrometry for clinical application: assay precision, stability, and correlation with MET gene amplification in FFPE tumor tissue. PLoS One. 2014;9:e100586.

24. Hembrough T, Henderson L, Rambo B et al. Quantification of HER2 from gastroesophageal cancer (GEC) FFPE tissue by mass spectrometry (MS). J Clin Oncol. 2014;32:abstr 17.

25. Seol H, Lee HJ, Choi $\mathrm{Y}$ et al. Intratumoral heterogeneity of HER2 gene amplification in breast cancer: its clinicopathological significance. Mod Pathol. 2012;25:938-948.

26. Lee HE, Park KU, Yoo SB, et al. Clinical significance of intratumoral HER2 heterogeneity in gastric cancer. Eur J Cancer. 2013;49:1448-57.

27. Arena V, Pennacchia I, Vecchio FM, Carbone A. HER-2 intratumoral heterogeneity. Mod Pathol. 2013;26:607-609.

28. Lee HJ, Park SY. Reply to 'Intratumoral heterogeneity of HER2 gene amplification in breast cancer: its clinicopathological significance'. Mod Pathol. 2013;26:610-611.

29. Nilsson T, Mann M, Aebersold R, et al. Mass spectrometry in high-throughput proteomics: ready for the big time. Nat Methods. 2010;7:681-5.

30. Addona TA, Abbatiello SE, Schilling B, et al. Multi-site assessment of the precision and reproducibility of multiple reaction monitoring-based measurements of proteins in plasma. Nat Biotechnol. 2009;27:633-41.

31. Whiteaker JR, Lin C, Kennedy J, et al. A targeted proteomicsbased pipeline for verification of biomarkers in plasma. Nat Biotechnol. 2011;29:625-34.

32. Catenacci DV, Cervantes G, Yala S, et al. RON (MST1R) is a novel prognostic marker and therapeutic target for gastroesophageal adenocarcinoma. Cancer Biol Ther. 2011;12:9-46.

33. Catenacci DV, Henderson L, Xiao SY, et al. Durable complete response of metastatic gastric cancer with anti-Met therapy followed by resistance at recurrence. Cancer Discov. 2011;1:573-9.

34. Catenacci D, Polite B, Henderson L et al. Towards personalized treatment for gastroesophageal adenocarcinoma (GEC): strategies to address tumor heterogeneity-PANGEA. J Clin Oncol. 2014;32:abstr 60.

35. Chia S. Testing for discordance at metastatic relapse: does it matter? J Clin Oncol Off J Am Soc Clin Oncol. 2012;30:575-6.

36. Yoon HH, Sukov WR, Shi Q, et al. HER-2/neu gene amplification in relation to expression of HER2 and HER3 proteins in patients with esophageal adenocarcinoma. Cancer. 2014;120:415-24.

37. Abrams J, Conley B, Mooney M et al. National Cancer Institute's Precision Medicine Initiatives for the new National Clinical Trials Network. Am Soc Clin Oncol Educ Book 2014;71-76.
38. Chen CT, Kim H, Liska D, et al. MET activation mediates resistance to lapatinib inhibition of HER2-amplified gastric cancer cells. Mol Cancer Ther. 2012;11:660-9.

39. Yonesaka K, Zejnullahu K, Okamoto I et al. Activation of ERBB2 signaling causes resistance to the EGFR-directed therapeutic antibody cetuximab. Sci Transl Med. 2011;3:99ra86.

40. Paulson AK, Linklater ES, Berghuis BD, et al. MET and ERBB2 are coexpressed in ERBB2+ breast cancer and contribute to innate resistance. Mol Cancer Res. 2013;11:1112-21.

41. Shattuck DL, Miller JK, Laederich M, et al. LRIG1 is a novel negative regulator of the Met receptor and opposes Met and Her2 synergy. Mol Cell Biol. 2007;27:1934-46.

42. Rusnak DW, Alligood KJ, Mullin RJ, et al. Assessment of epidermal growth factor receptor (EGFR, ErbB1) and HER2 (ErbB2) protein expression levels and response to lapatinib (Tykerb, GW572016) in an expanded panel of human normal and tumour cell lines. Cell Prolif. 2007;40:580-94.

43. Zhang XL, Yang YS, Xu DP, et al. Comparative study on overexpression of HER2/neu and HER3 in gastric cancer. World J Surg. 2009;33:2112-8.

44. Yoon HH, Shi Q, Sukov WR, et al. Adverse prognostic impact of intratumor heterogeneous HER2 gene amplification in patients with esophageal adenocarcinoma. J Clin Oncol Off J Am Soc Clin Oncol. 2012;30:3932-8.

45. Verma S, Miles D, Gianni L, et al. Trastuzumab emtansine for HER2-positive advanced breast cancer. New Engl J Med. 2012;367:1783-91.

46. von Minckwitz G, du Bois A, Schmidt M, et al. Trastuzumab beyond progression in human epidermal growth factor receptor 2-positive advanced breast cancer: a German Breast Group 26/Breast International Group 03-05 study. J Clin Oncol. 2009;27:1999-2006.

47. Geyer CE, Forster J, Lindquist D, et al. Lapatinib plus capecitabine for HER2-positive advanced breast cancer. New Engl J Med. 2006;355:2733-43.

48. Blackwell KL, Burstein HJ, Storniolo AM, et al. Overall survival benefit with lapatinib in combination with trastuzumab for patients with human epidermal growth factor receptor 2-positive metastatic breast cancer: final results from the EGF104900 Study. J Clin Oncol. 2012;30:2585-92.

49. Moasser MM. Two dimensions in targeting HER2. J Clin Oncol. 2014;32:2074-7.

50. Baselga J, Cortes J, Kim SB, et al. Pertuzumab plus trastuzumab plus docetaxel for metastatic breast cancer. New Engl J Med. 2012;366:109-19. 